\title{
Boric Acid Catalyzed Methyl Esterification of Sugar Acids
}

\author{
Stephan M. Levonis ${ }^{A}$, Brighid B. Pappin ${ }^{A}$, Alissa Sharp ${ }^{A}$, Milton J. Kiefel $^{A, B}$ and $^{A, B}$ \\ ${ }^{A}$ Institute for Glycomics and School of Biomolecular and Physical Sciences, Gold Coast Campus, Griffith \\ University, QLD 4222, Australia \\ ${ }^{\mathrm{B}}$ Corresponding authors: E-mail: M.Kiefel@griffith.edu.au, T.Houston@griffith.edu.au
}

\section{Table of Contents Graphic:}

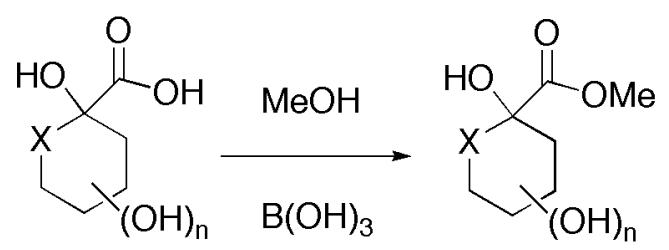

\begin{abstract}
Boric acid catalyzes methyl esterification of certain sugar acids (sialic acid, KDN) and related natural products (quinic acid) quite cleanly in some cases. However, closely related sugar acids (glucuronic acid, KDO) failed to esterify under the same conditions. Factors governing this dichotomy are discussed.
\end{abstract}

Boron is abundant in nature as boric acid in seawater or within vast borate mineral deposits in Turkey and the USA. ${ }^{1}$ It is an important trace element required for healthy plant growth and an ultra-trace element supporting brain and bone development in humans. Boric acid has much lower toxicity in mammals than either alkyl- or arylboronic acids and thus has great potential in the development of green chemistry. Boron acids have been widely developed over half a century as catalysts for amide bond formation $^{2}$ and less extensively for catalysis of esterification. ${ }^{3}$ In 2004 we reported use of boric acid for the chemoselective esterification of $\alpha$-hydroxycarboxylates using an alcohol as solvent. ${ }^{4}$ Following this, Ishihara and Yamamoto showed such reactions could be accelerated by reducing the alcohol to stoichiometric levels relative to the $\alpha$-hydroxy 
carboxylic acid. ${ }^{5}$ The observed acceleration is attributed to higher levels of bis $(\alpha$ hydroxycarboxylate)borate complex, a more reactive species than that of a single $\alpha$ hydroxycarboxylate ligand on the boron (Scheme 1). We have taken advantage of such a pathway in the selective monoesterification of malonic acid. ${ }^{6}$

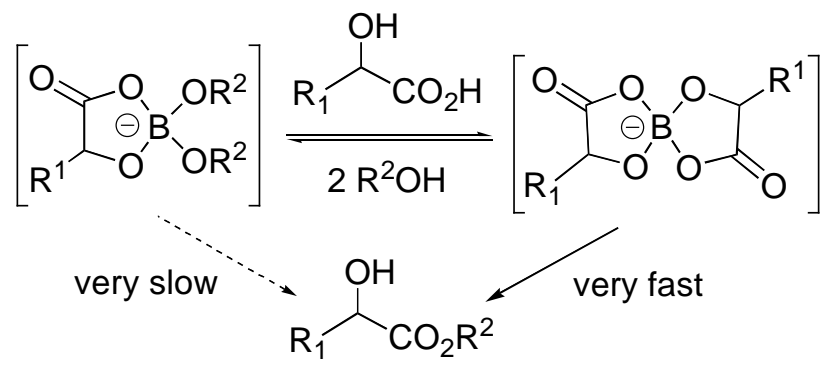

Scheme 1. Two pathways of boric acid catalyzed esterification.

Many natural carbohydrates contain carboxylic acids proximal to hydroxyl groups as part of their structures. These systems offer an additional level of complexity to test the broad applicability of boric acid as a chemoselective esterification catalyst. Initially, the free hydroxyl groups of the monosaccharide can compete, either in an inter- or intramolecular sense, toward esterification of the activated carboxylate. Once ester product is formed, this compound may still contain diols capable of sequestering the boric acid with high affinity thus slowing catalytic turnover. Herein, we report examples of clean methyl esterification of sugar acids catalysed by boric acid in methanol and cases involving closely related systems where ester formation is not observed.

First, reaction with the canonical sialic acid $N$-acetylneuraminic acid (Neu5Ac) was sluggish at room temperature using $20 \mathrm{~mol} \%$ boric acid in dry methanol solvent (Fig. 1). However, gentle heating $\left(50^{\circ} \mathrm{C}\right)$ resulted in smooth conversion to the methyl ester (ca. 90\%) with no significant bi-products detected by HPLC. Reaction with the closely related member of the sialic acid family KDN (deaminated neuraminic acid) resulted in methyl ester formation (ca. 30-50\%) at ambient temperature but gave a mixture upon heating. ${ }^{7}$

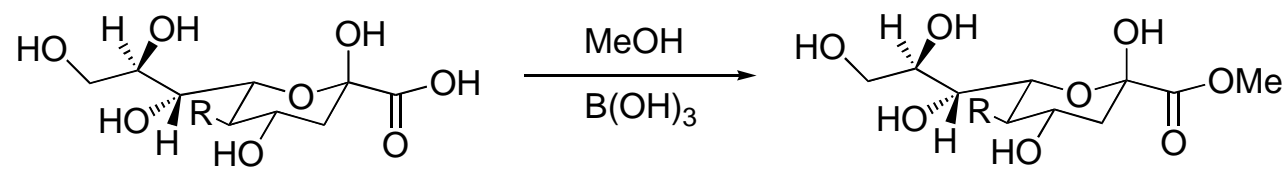

$\mathrm{R}=\mathrm{NHAc}(\mathrm{Neu} 5 \mathrm{Ac})$ or $\mathrm{OH}(\mathrm{KDN})$

Figure 1. Boric acid catalysis of sialic acid esterification 
It is to be expected that boric acid converts to a high degree to trimethylborate in solution and activates Neu5Ac by the "slower" pathway as defined in Scheme 1. The chemoselective nature of $\alpha$-hydroxycarboxylate activation we observed previously ${ }^{4}$ discounts a mixed anhydride between the carboxylate and the boric acid as the primary method of activation.

Quinic acid also transformed smoothly to its methyl ester at room temperature in high conversion (>90\%) with only 10 mol\% boric acid (Fig. 2). Attempts to esterify quinic acid with 1 equiv. of either 2-phenylethanol or benzyl alcohol using $10 \mathrm{~mol} \%$ boric acid in MeCN were unsuccessful (0-5\% conversion after $24 \mathrm{~h}$ ). It is likely that the presence of a competing ligation site for the boron, the cis-vicinal diol trans-annular to the $\alpha$-hydroxycarboxylate, reduces the ability of the catalyst to activate the latter. The low boiling point of methanol and the low solubility of sugar acids in toluene prevent use of this solvent under azeotropic conditions to drive methyl esterification under boric acid catalysis. $^{5}$

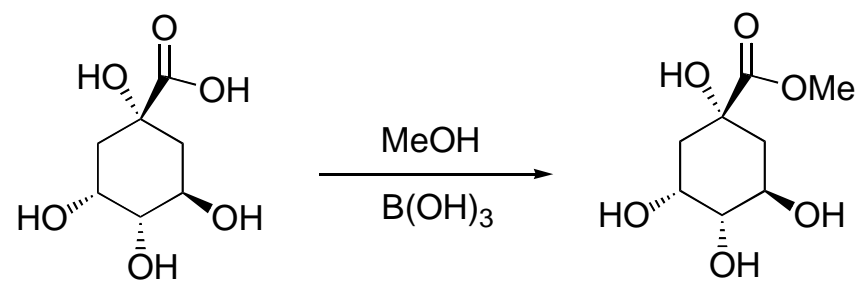

Figure 2. Boric acid catalysis of quinic acid esterification

Surprisingly, several sugar acids failed to esterify under boric acid catalysis over a range of reaction conditions (Fig. 3). Glucuronic acid contains a $\beta$-hydroxycarboxylate motif but failed to esterify under boric acid catalysis in methanol. Previous work has shown that $\beta$-hydroxycarboxylates such as salicylic acid can be readily esterified under similar conditions ${ }^{8}$ although relative to aliphatic alcohols phenolic hydroxyl groups tend to exchange more readily with boron acids. The lack of reactivity of glucuronate may be due to the competing binding sites, specifically the C1/2-diol, available for the borate. The bacterial monosaccharide 3-deoxy-D-manno-oct-2-ulosonate (KDO) also failed to esterify over a range of conditions including microwave irradiation and excess boric acid 
(1.1-3.0 equiv.). This hexose is both acid- and base-labile and difficult to esterify other than by reaction with diazomethane. As there are three competing boron binding sites on $\mathrm{KDO}$, esterification was attempted on 5-deoxy $\mathrm{KDO}^{9}$, but elimination of the cis-vicinal diol failed to facilitate methyl ester production. Finally, open chain glucose derivatives such as gluconic acid lack sufficient solubility in methanol for efficient esterification under boric acid catalysis.

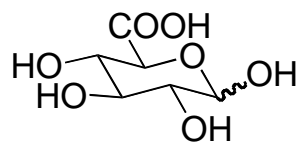

Glucuronic acid

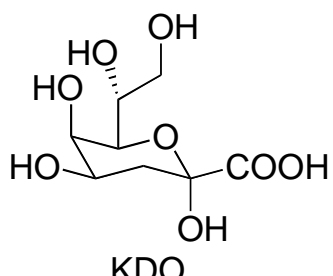

$\mathrm{KDO}$

Figure 3. Sugar acids that failed to esterify using boric acid.

Boric acid catalysed methyl esterification of sugar acids proceeds with high efficiency in certain systems but is highly substrate dependent. The differences in conversion are quite striking: approaching quantitative yields in some cases with no detectable ester formation in others. Since the reaction involves an overall dehydration, the presence of water retards esterification and anhydrous methanol is preferable as solvent. This fact is important to our research using fluorescent boronates as sensors for sugar acids. ${ }^{10}$ As we generally use methanol/aqueous buffer systems for these experiments, we have taken care to ensure that esterification does not occur in these cases. However, under anhydrous conditions certain sugar acids and many $\alpha$ hydroxycarboxylates are readily esterified by boric acid catalysis. As boric acid is an abundant, environmentally-benign resource, it should find further application to a wide range of reactions. We have recently developed a simple method to extract boron from seawater for use in catalysis and will report on this in due course. 


\section{Experimental Section:}

Sialic acid methyl ester: To a stirred solution of sialic acid (200 mg, $0.68 \mathrm{mmol}$ ) in anhydrous methanol (2 mL) was added boric acid (8-20 mg, 0.13-0.33 mmol). The solution was stirred under nitrogen at $50^{\circ} \mathrm{C}$. After 24 hours this mixture was concentrated by vacuum and the residue was redissolved in methanol and again concentrated under vacuum. Ester formation was confirmed by ${ }^{1} \mathrm{H}$ NMR spectroscopy as compared to literature values ${ }^{11}$ (yield ca. $90 \%$ or greater in all cases). ${ }^{1} \mathrm{H}$ NMR $\left(\mathrm{D}_{2} \mathrm{O} 300 \mathrm{MHz}\right) \delta 1.88$ (dd, 1H, H3 $3_{\mathrm{ax}}, J=12.3,10.8 \mathrm{~Hz}$ ), 2.03 (s, 3H, NHAc), 2.28 (dd, 1H, H3 ${ }_{\text {eq }} J=12.9,4.5$ Hz), 3.50 (dd, 1H, H7), 3.58 (dd, 1H, H9, $J=11.7,6$ Hz), 3.70 (ddd, 1H, H8, $J=9$, 6.3, $2.4 \mathrm{~Hz}$ ), 3.80 (m, 1H, H9), 3.81 (s, 3H, $\mathrm{OCH}_{3}$ ), 3.91 (m, 1H, H5), 4.0-4.1 (m, 2H); MS $\left(\right.$ ESI+) $346.1\left(\mathrm{M}+\mathrm{Na}^{+}\right)$.

Quinic acid methyl ester: To a stirred solution of quinic acid (200 mg, $1.04 \mathrm{mmol}$ ) in methanol (anhydrous, $2 \mathrm{~mL}$ ) was added boric acid (7 mg, $0.11 \mathrm{mmol}$ ). The solution was stirred at room temperature for 24 hours and concentrated by vacuum as described above. NMR spectroscopy confirmed product as compared to literature values ${ }^{12}$ (yield $>90 \%$ ). ${ }^{1} \mathrm{H}$ NMR (300 MHz, CD $\left.{ }_{3} \mathrm{OD}\right) \delta 1.86$ (dd, 1H, H3 $\mathrm{ax}, J=8.2,7.6 \mathrm{~Hz}$ ), 2.0-2.15 (m, 3H), 3.41 (dd, 1H, H5, $J=8.7,3.3 \mathrm{~Hz}$ ), 3.72 (s, 3H, OMe), 3.99 (ddd, 1H, H4, $J=13.5$, 8.2, $4.2 \mathrm{~Hz}$ ), 4.07 (m, 1H, H6); MS (ESI+) $228.9\left(\mathrm{M}+\mathrm{Na}^{+}\right)$.

Acknowledgment. We wish to thank the Institute for Glycomics and Griffith University for financial support. 


\section{References:}

[1] (a) CRC Handbook for Chemistry and Physics, 1984, R. C. Weast, Ed., 65 ${ }^{\text {th }}$ Edition, CRC Press: Florida. (b) T. A. Houston, Aust. J. Chem. 2011, 64, 1415.

[2] (a) Nelson, A. Pelter, J. Chem. Soc. 1965, 5142. (b) D. Collum, Chen, B. Ganem, J. Org. Chem. 1978, 43, 4393. (c) K. Ishihara, S. Ohara, H. Yamamoto, J. Org. Chem. 1996, 61, 4196. (d) K. Arnold, B. Davies, R. L. Giles, C. Grosjean, G. E. Smith, A. Whiting, Adv. Synth. Catal. 2006, 348, 813. (e) T. Maki, K. Ishihara, H. Yamamoto, Tetrahedron 2007, 63, 8645. (f) R. M. Al-Zouby, O. Marion, D. G. Hall, Angew. Chem. Int. Ed. 2008, 47, 2876. (g) H. Charville, D. Jackson, G. Hodges, A. Whiting, Chem. Commun. 2010, 46, 1816. (h) N. Gernigon, R. M. Al-Zouby, D. G. Hall, J. Org. Chem. 2012, 77, 8386 and references therein.

[3] (a) W. W. Lawrence, Jr. Tetrahedron Lett. 1971, 12, 3453. (b) Y. Mansoori, F. S. Tataroglu, M. Sadaghian, Green Chem. 2005, 7, 870. (c) T. A. Houston, S. M. Levonis, M. J. Kiefel, Aust. J. Chem. 2007, 60, 811 and references therein.

[4] T. A. Houston, B. L. Wilkinson, J. T. Blanchfield, Org. Lett. 2004, 6, 679.

[5] T. Maki, K. Ishihara, H. Yamamoto, Org. Lett. 2005, 7, 5047.

[6] S. M. Levonis, L. F. Bornaghi, T. A. Houston, Aust. J. Chem. 2007, 60, 821.

[7] Prolonged heating of the $\mathrm{KDN}$ reaction at $50^{\circ} \mathrm{C}$ resulted in appearance of a second product, presumably the methyl glycoside of the methyl ester.

[8] (a) S. Solomon, C. Hur, A. Lee, K. Smith, J. Chem. Educ. 1996, 73, 173. (b) S. M. Levonis, M. J. Kiefel, T. A. Houston, P. C. Healy, Acta Cryst. 2010, E66, o226. [9] R. Winzar, J. Philips, M. J. Kiefel, Synlett 2010, 583.

[10] (a) S. M. Levonis, M. J. Kiefel, T. A. Houston, Chem. Commun. 2009, 2278. (b) T. A. Houston, S. M. Levonis, M. J. Kiefel, Aust. J. Chem. 2011, 64, 1454.

[11] A. Malapelle, A. Coslovi, G. Doisneau, J.-M. Beau, Eur. J. Org. Chem. 2007, 3145.

[12] M. G. Banwell, N. L. Hungerford, K. A. Jolliffe, Org. Lett. 2004, 6, 2737. 